\title{
Best proximity points of discontinuous operator in partially ordered metric spaces
}

\author{
B. S. Choudhury ${ }^{a}$, M. Jleli ${ }^{b, *}$, P. Maity ${ }^{a}$ \\ ${ }^{a}$ Department of Mathematics, Indian Institute of Engineering Science and Technology, Shibpur, Howrah-711103, West Bengal, India. \\ ${ }^{b}$ Department of Mathematics, College of Science, King Saud University, P. O. Box 2455, Riyadh 11451, Saudi Arabia.
}

Communicated by B. Samet

\begin{abstract}
In this paper we establish best proximity point results for monotone multivalued mappings in partially ordered metric spaces. We consider three notions of monotonicity of multivalued mappings. The main theorem is obtained by utilizing property $U C$ and MT-functions. There is no requirement of continuity on the multivalued function which is illustrated with two supporting examples of the results established in this paper. There are two corollaries. Some existing results are extended to the domain of partially ordered metric spaces through one of the corollaries. (C)2017 all rights reserved.
\end{abstract}

Keywords: Best proximity point, multivalued cyclic mapping, multivalued approximately monotone increasing mapping, multivalued partly monotone increasing mapping.

2010 MSC: 54H10, 54H25, 47H10.

\section{Introduction and preliminaries}

Best proximity points are concepts related to non-self mappings. They are generalizations of fixed points in that they reduce to fixed points whenever the domain and codomain have non-null intersection. They are intended to find minimum distances between two sets.

Definition 1.1. Let $A$ and $B$ be two subsets of a metric space $(X, d), T: A \rightarrow B$ be a mapping, then a point $z \in A$ is called a best proximity point if $d(z, T z)=d(A, B)$, where $d(A, B)=\inf \{d(x, y): x \in A, y \in B\}$.

Essentially, the best proximity point problem is a global optimality problem where we seek to minimize $d(z, T z)$ over $z \in A$ with the constraint that the minimum distance is achieved with value $d(A, B)$. Technically, we can also treat the problem as an approximate fixed point problem, that is, we can solve the problem by finding an optimal approximate solution of the fixed point equation $x=T x$ while there being no exact solution in the case where $A \cap B=\phi$. We adopt the above mentioned approach in the paper. It may be pointed out that these results being optimality results are very different from approximation

\footnotetext{
${ }^{*}$ Corresponding author Maity)

Email addresses: binayak12@yahoo.co.in (B. S. Choudhury), jleli@ksu.edu.sa (M. Jleli), pranati.math@gmail.com (P. 
results. As an instance, the famous Ky Fan's approximation theorem [17] is not an optimality result. Best proximity points were introduced in [21]. The literature in this subject has developed rapidly. Some of the recent works are noted here $[4,7-9,12,13,19,20]$.

Our results are derived in the general context where the domain and co-domain are subsets of a metric space. There is no requirement of continuity on the function. In fact we illustrate our result with discontinuous functions. We assume the existence of partial order in metric spaces. Partial order in metric fixed point problems was initiated by Turinici [28] in uniform spaces which was followed by a large number of papers like $[3,5,6,11]$. The existence of best proximity point in partially ordered metric spaces was first studied in [1]. The best proximity point result in such spaces appeared in $[2,18,25,26]$. Further we use MT-function in our result which was introduced in [22] and was used in works like [8, 10, 14, 15]. Also we use property UC of the space which was introduced in [27] and was utilized in a good number of papers on best proximity point problems $[2,8]$.

Definition 1.2 (Cyclic mapping [16]). Let $A, B$ be two nonempty subsets of a metric space (X,d). A mapping $T: A \cup B \rightarrow A \cup B$ is said to be a cyclic mapping if $T x \in B$, for all $x \in A$ and $T y \in A$, for all $y \in B$.

The following are the concepts from set-valued analysis which we use in this paper. Let $(X, d)$ be a metric space. Then

$$
\mathrm{CB}(\mathrm{X})=\{\mathrm{A}: \mathrm{A} \text { is a non-empty closed and bounded subset of } \mathrm{X}\} .
$$

We use Hausdorff metric in our paper which is a metric defined on $\mathrm{CB}(\mathrm{X})$ as follows:

Definition 1.3 (Hausdorff distance [23]). Let $(X, d)$ be a metric space. Then the Hausdorff metric $\mathrm{H}$ introduced by $d$ is defined as follows.

For $A, B \in C B(X), H(A, B)=\max \left\{\sup _{x \in A} d(x, B), \sup _{y \in B} d(y, A)\right\}$, where, for any $C \in C B(X), x \in X$, $d(x, C)=\inf \{d(x, y): y \in C\}$.

We call a mapping $\mathrm{T}: X \rightarrow \mathrm{CB}(\mathrm{X})$ continuous if it continuous as a mapping from the metric space $(X, d)$ to $(C B(X), H)$.

If $(X, d)$ is a complete metric space, then $(C B(X), H)$ is also complete [23].

Definition 1.4 (Multivalued cyclic mapping [24]). Let $A, B$ be two nonempty subsets of a metric space $(X, d)$. A multivalued mapping $T: A \cup B \rightarrow C B(A) \cup C B(B)$ is said to be a multivalued cyclic mapping if $T x \in C B(B)$, for all $x \in A$ and $T y \in C B(A)$, for all $y \in B$.

In the following three definitions we note the monotone property of multivalued mappings in three different ways.

Definition 1.5 (Multivalued monotone increasing mapping). A multivalued mapping $T: X \rightarrow 2^{X}$ where $(X, \preceq)$ is a partially ordered set, is said to be monotone increasing if $x \preceq y$ and $y \in T x$ implies that $a \preceq b$ whenever $a \in T x$ and $b \in T y$.

Definition 1.6 (Multivalued approximately monotone increasing mapping). A multivalued mapping $T$ : $X \rightarrow 2^{X}$ where $(X, \preceq)$ is a partially ordered set, is said to be a approximately monotone increasing if $x \preceq y$ and $y \in T x$ implies that $y \preceq z$ whenever $z \in T y$.

Definition 1.7 (Multivalued partly monotone increasing mapping). Let $(X, d, \preceq)$ be a metric space with a partial order. Let $S$ be a subset of $X$. A multivalued mapping $T: S \rightarrow 2^{X}$ is said to be partly monotone increasing if $x, y \in S$ with $x \preceq y$ and $y \in T x$ implies that there exists $z \in T y$ such that $y \preceq z$ and $d(y, z) \leqslant H(T x, T y)$.

It is apparent that in a metric space with a partial order $(X, d, \preceq)$, Definition 1.5 implies Definition 1.6 and Definition 1.6 in turn implies Definition 1.7, that is, Definition 1.5 to Definition 1.7 are gradually weaker definitions. 
When $T$ is a single-valued mapping, that is, in the case, when $T: X \rightarrow X$, all the above Definitions 1.51.7 reduce to the usual definition of monotone increasing operator with the metric inequality in Definition 1.7 being trivial.

Definition 1.8 (Property UC [27]). Let $A$ and $B$ be two nonempty subsets of a metric space $(X, d)$. Then $(A, B)$ is said to satisfy the property $U C$ if the following holds:

If $\left\{x_{n}\right\}$ and $\left\{x_{n}^{\prime}\right\}$ are sequences in $A$ and $\left\{y_{n}\right\}$ is a sequence in $B$ such that $\lim _{n \rightarrow \infty} d\left(x_{n}, y_{n}\right)=d(A, B)$ and $\lim _{n \rightarrow \infty} d\left(x_{n}^{\prime}, y_{n}\right)=d(A, B)$, then $\lim _{n \rightarrow \infty} d\left(x_{n}, x_{n}^{\prime}\right)=0$.

Definition 1.9 (MT-function [22]). A function $\phi:[0, \infty) \rightarrow[0,1)$ is said to be an MT-function (or Rfunction) if it satisfies Mizoguchi-Takahashi's condition, that is, $\limsup _{s \rightarrow t^{+}} \phi(s)<1$ for all $t \in[0, \infty)$.

Lemma $1.10([14])$. Let $\phi:[0, \infty) \rightarrow[0,1)$ be an MT-function (or R-function). Then for any non-increasing sequence $\left\{\mathrm{t}_{\mathrm{n}}\right\}$ in $[0, \infty)$,

$$
0 \leqslant \sup _{n \in N} \phi\left(t_{n}\right)<1 .
$$

Lemma 1.11 ([27]). Let A and B be subsets of a metric space (X, d). Assume that (A, B) has the property UC. Let $\left\{x_{n}\right\}$ and $\left\{y_{n}\right\}$ be sequences in $A$ and $B$, respectively, such that the following holds:

$$
\lim _{n \rightarrow \infty} \sup _{m \geqslant n} d\left(x_{m}, y_{n}\right)=d(A, B) .
$$

Then $\left\{x_{m}\right\}$ is a Cauchy sequence.

\section{Main results}

Theorem 2.1. Let $(X, \mathrm{~d}, \preceq)$ be a partially ordered complete metric space, and $\mathrm{A}$ and $\mathrm{B}$ be two nonempty closed subsets of $\mathrm{X}$ such that $(\mathrm{A}, \mathrm{B})$ and $(\mathrm{B}, \mathrm{A})$ satisfy the property $U C$. Let $\mathrm{T}: \mathrm{A} \cup \mathrm{B} \rightarrow \mathrm{CB}(\mathrm{A}) \cup \mathrm{CB}(\mathrm{B})$ be a multivalued cyclic mapping such that

(i) $\mathrm{T}$ is partly monotone increasing on $\mathrm{A} \cup \mathrm{B}$;

(ii) there exists $x_{0} \in A$ such that $x_{0} \preceq x_{1}$ and $x_{1} \in T x_{0}$ for some $x_{1} \in B$;

(iii)

$$
H(T x, T y) \leqslant \phi(d(x, y)) d(x, y)+(1-\phi(d(x, y))) d(A, B),
$$

where $x \in A$ and $y \in B$, either $x \preceq y$ or $y \preceq x$ and $\phi$ is an MT-function;

(iv) for any monotone increasing sequence $\left\{x_{n}\right\}$ in $X$ such that $\left\{x_{n}\right\} \rightarrow x$, the relation $x_{n} \preceq x$ holds for all $n$.

Then $\mathrm{T}$ has a best proximity point in A.

Proof. From the assumption (ii) of the theorem there exist $x_{0} \in A$ and $x_{1} \in B$ such that $x_{1} \in T x_{0}$ and $x_{0} \preceq x_{1}$. By the partly increasing property of $T$, there exists $x_{2} \in T x_{1} \subset A$ such that $x_{1} \preceq x_{2}$ and $\mathrm{d}\left(\mathrm{x}_{1}, \mathrm{x}_{2}\right) \leqslant \mathrm{H}\left(T \mathrm{x}_{0}, T \mathrm{x}_{1}\right)$. Then, by (2.1), we have

$$
d\left(x_{1}, x_{2}\right) \leqslant H\left(T x_{0}, T x_{1}\right) \leqslant \phi\left(d\left(x_{0}, x_{1}\right)\right) d\left(x_{0}, x_{1}\right)+\left(1-\phi\left(d\left(x_{0}, x_{1}\right)\right)\right) d(A, B) .
$$

Again, by the partly increasing property of $T$, there exists $x_{3} \in T x_{2} \subset B$ such that $x_{2} \preceq x_{3}$ and $d\left(x_{2}, x_{3}\right) \leqslant$ $\mathrm{H}\left(\mathrm{Tx_{1 }}, \mathrm{Tx_{2 }}\right)$. Then,

$$
d\left(x_{2}, x_{3}\right) \leqslant H\left(T x_{1}, T x_{2}\right) \leqslant \phi\left(d\left(x_{1}, x_{2}\right)\right) d\left(x_{1}, x_{2}\right)+\left(1-\phi\left(d\left(x_{1}, x_{2}\right)\right)\right) d(A, B) .
$$


Proceeding in this way, generally, we have, for all $n \geqslant 1, x_{n} \preceq x_{n+1}$,

$$
x_{n+1} \in T x_{n} \text { with } x_{2 n} \in A, \quad x_{2 n+1} \in B,
$$

such that

$$
d\left(x_{n}, x_{n+1}\right) \leqslant H\left(T x_{n-1}, T x_{n}\right) \leqslant \phi\left(d\left(x_{n-1}, x_{n}\right)\right) d\left(x_{n-1}, x_{n}\right)+\left(1-\phi\left(d\left(x_{n-1}, x_{n}\right)\right)\right) d(A, B),
$$

that is, for all $n \geqslant 1$,

$$
d\left(x_{n}, x_{n+1}\right)-d(A, B) \leqslant \phi\left(d\left(x_{n-1}, x_{n}\right)\right)\left[d\left(x_{n-1}, x_{n}\right)-d(A, B)\right] .
$$

Since $\phi(t)<1$ for all $t \in[0, \infty)$, it follows that for all $n \geqslant 1$,

$$
d\left(x_{n}, x_{n+1}\right)-d(A, B)<d\left(x_{n-1}, x_{n}\right)-d(A, B),
$$

that is, for all $n \geqslant 1$,

$$
d\left(x_{n}, x_{n+1}\right)<d\left(x_{n-1}, x_{n}\right),
$$

that is, $\left\{d\left(x_{n}, x_{n+1}\right)\right\}$ is a strictly decreasing sequence of positive real numbers. Hence $\lim _{n \rightarrow \infty} d\left(x_{n}, x_{n+1}\right)$ exists. Also, since $\phi$ is an MT-function and $\left\{d\left(x_{n}, x_{n+1}\right)\right\}$ is a strictly decreasing sequence in $[0, \infty)$, by Lemma 1.10, we get

$$
0 \leqslant \sup _{n \in N} \phi\left(d\left(x_{n}, x_{n+1}\right)\right)<1 .
$$

Let $\lambda=\sup _{n \in N} \phi\left(d\left(x_{n}, x_{n+1}\right)\right)$, where $\lambda \in[0,1)$. Then

$$
0 \leqslant \phi\left(d\left(x_{n}, x_{n+1}\right)\right) \leqslant \lambda<1 \text { for all } n \in N .
$$

By repeated applications of (2.3), we get

$$
\begin{aligned}
d\left(x_{n}, x_{n+1}\right)-d(A, B) & \leqslant \phi\left(d\left(x_{n-1}, x_{n}\right)\right)\left[d\left(x_{n-1}, x_{n}\right)-d(A, B)\right] \\
& \leqslant \lambda\left[d\left(x_{n-1}, x_{n}\right)-d(A, B)\right] \\
& \leqslant \lambda^{2}\left[d\left(x_{n-2}, x_{n-1}\right)-d(A, B)\right] \\
& \vdots \\
& \leqslant \lambda^{n}\left[d\left(x_{0}, x_{1}\right)-d(A, B)\right] .
\end{aligned}
$$

Taking limit $n \rightarrow \infty$ in the above inequality, we get

$$
\lim _{n \rightarrow \infty} d\left(x_{n}, x_{n+1}\right)=d(A, B) .
$$

Then, from (2.5), we have

$$
\lim _{n \rightarrow \infty} d\left(x_{2 n}, x_{2 n+1}\right)=d(A, B)
$$

and

$$
\lim _{n \rightarrow \infty} d\left(x_{2 n+2}, x_{2 n+1}\right)=d(A, B) .
$$

Since $x_{2 n}$ and $x_{2 n+2}$ are two sequences in $A$, and $x_{2 n+1}$ is sequence in $B$ where $(A, B)$ satisfies the property $U C$, from (2.6) and (2.7), we conclude that

$$
\lim _{n \rightarrow \infty} d\left(x_{2 n}, x_{2 n+2}\right)=0 .
$$

Since the pair $(B, A)$ also satisfies the property $U C$, using (2.5) and by a similar argument, we have

$$
\lim _{n \rightarrow \infty} d\left(x_{2 n-1}, x_{2 n+1}\right)=0 .
$$


Next we prove that $\left\{x_{2 n}\right\}$ is a Cauchy sequence in $A$. For that purpose we first establish that

$$
\lim _{n \rightarrow \infty, m \geqslant n} d\left(x_{2 m}, x_{2 n+1}\right)=d(A, B),
$$

which is the same as establishing that for given $\epsilon>0$ we can find a positive integer $N$ such that for all $m \geqslant n>N$,

$$
d\left(x_{2 m}, x_{2 n+1}\right) \leqslant d(A, B)+\epsilon .
$$

If (2.11) is not valid, then, particularly in view of (2.6), there exist $\epsilon>0$ and a natural number $k_{0}$ such that for each $k \geqslant k_{0}$ there exist $m(k)>n(k)>k$ for which

$$
d\left(x_{2 m(k)}, x_{2 n(k)+1}\right)>d(A, B)+\epsilon
$$

and additionally

$$
d\left(x_{2 m(k)-2,} x_{2 n(k)+1}\right) \leqslant d(A, B)+\epsilon .
$$

Then, by (2.11) and (2.12), for all $k \geqslant 1$,

$$
\begin{aligned}
d(A, B)+\epsilon & <d\left(x_{2 m(k)}, x_{2 n(k)+1}\right) \\
& \leqslant d\left(x_{2 m(k)}, x_{2 m(k)-2}\right)+d\left(x_{2 m(k)-2}, x_{2 n(k)+1}\right) \\
& \leqslant d\left(x_{2 m(k)}, x_{2 m(k)-2}\right)+d(A, B)+\epsilon .
\end{aligned}
$$

Taking $k \rightarrow \infty$, and using (2.8), we obtain

$$
\lim _{k \rightarrow \infty} d\left(x_{2 m(k)}, x_{2 n(k)+1}\right)=d(A, B)+\epsilon .
$$

Then, for all $k \geqslant 1$,

$$
\begin{aligned}
& d\left(x_{2 m(k)}, x_{2 n(k)+1}\right) \leqslant d\left(x_{2 m(k)}, x_{2 m(k)+2}\right)+d\left(x_{2 m(k)+2}, x_{2 n(k)+3}\right)+d\left(x_{2 n(k)+3}, x_{2 n(k)+1}\right) \\
& <\mathrm{d}\left(\mathrm{x}_{2 \mathrm{~m}(\mathrm{k})}, \mathrm{x}_{2 \mathrm{~m}(\mathrm{k})+2}\right)+\mathrm{d}\left(\mathrm{x}_{2 \mathrm{~m}(\mathrm{k})+1}, \mathrm{x}_{2 \mathrm{n}(\mathrm{k})+2}\right) \\
& +\mathrm{d}\left(\mathrm{x}_{2 \mathrm{n}(\mathrm{k})+3}, \mathrm{x}_{2 \mathrm{n}(\mathrm{k})+1}\right)(\text { by }(2.4)) \\
& \leqslant d\left(x_{2 m(k)}, x_{2 m(k)+2}\right)+d\left(x_{2 n(k)+3}, x_{2 n(k)+1}\right) \\
& +\mathrm{H}\left(T x_{2 m(k)}, T x_{2 n(k)+1}\right) \text { (by the first inequality of (2.2)) } \\
& \leqslant d\left(x_{2 m(k)}, x_{2 m(k)+2}\right)+d\left(x_{2 n(k)+3}, x_{2 n(k)+1}\right) \\
& +\phi\left(d\left(x_{2 m(k)}, x_{2 n(k)+1}\right)\right) d\left(x_{2 m(k)}, x_{2 n(k)+1}\right) \\
& +\left(1-\phi\left(\mathrm{d}\left(\mathrm{x}_{2 \mathrm{~m}(\mathrm{k})}, \mathrm{x}_{2 \mathrm{n}(\mathrm{k})+1}\right)\right) \mathrm{d}(\mathrm{A}, \mathrm{B})(\text { by }(2.1))\right. \\
& =\mathrm{d}\left(\mathrm{x}_{2 \mathrm{~m}(\mathrm{k})}, \mathrm{x}_{2 \mathrm{~m}(\mathrm{k})+2}\right)+\mathrm{d}\left(\mathrm{x}_{2 \mathrm{n}(\mathrm{k})+3}, \mathrm{x}_{2 \mathrm{n}(\mathrm{k})+1}\right)+\mathrm{d}(\mathrm{A}, \mathrm{B}) \\
& +\phi\left(d\left(x_{2 m(k)}, x_{2 n(k)+1}\right)\left[d\left(x_{2 m(k)}, x_{2 n(k)+1}\right)-d(A, B)\right]\right. \text {. }
\end{aligned}
$$

By (2.12) and (2.13), since $\phi$ is an MT-function (Definition 1.9), it follows that

$$
\delta=\lim _{k \rightarrow \infty} \sup \phi\left(d\left(x_{2 m(k)}, x_{2 n(k)+1}\right)\right) \leqslant \lim _{s \rightarrow(d(A, B)+\epsilon)^{+}} \sup \phi(s)<1 .
$$

Taking limsup as $k \rightarrow \infty$ in (2.14), using (2.8), (2.9), and (2.12), we have

$$
d(A, B)+\epsilon \leqslant d(A, B)+\delta \epsilon,
$$

which is a contradiction since $\delta<1$ by (2.15). This establishes (2.11) and hence (2.10). Then by Lemma $1.11,\left\{x_{2 m}\right\}$ is a Cauchy sequence in $A$. The set $A$ being closed in the complete metric space $X$, there exists $x \in A$ such that

$$
x_{2 n} \rightarrow x \text { as } \mathrm{n} \rightarrow \infty .
$$


Since $x \in A$ and $x_{2 n-1} \in B$, we have

$$
d(A, B) \leqslant d\left(x, x_{2 n-1}\right) \leqslant d\left(x, x_{2 n}\right)+d\left(x_{2 n}, x_{2 n-1}\right) .
$$

Taking limit $n \rightarrow \infty$ in the above inequality and using (2.6) and (2.16), we have

$$
\lim _{n \rightarrow \infty} d\left(x, x_{2 n-1}\right)=d(A, B) .
$$

Now, by construction, $x_{2 n} \preceq x_{2 n+2} \preceq x_{2 n+4} \preceq \cdots$.

Therefore, by condition (iv) of our theorem, $x_{2 n} \preceq x$ for all $n$.

Again, $x_{2 n-1} \preceq x_{2 n}$ and $x_{2 n} \preceq x$. Therefore, $x_{2 n-1} \preceq x$ for all $n$.

Using (2.1), we have

$$
\begin{aligned}
d(A, B) & \leqslant d(x, T x) \\
& \leqslant d\left(x, x_{2 n}\right)+d\left(x_{2 n}, T x\right) \\
& \leqslant d\left(x, x_{2 n}\right)+H\left(T x_{2 n-1}, T x\right) \quad\left(\text { since } x_{2 n} \in T x_{2 n-1}\right) \\
& \leqslant d\left(x, x_{2 n}\right)+\phi\left(d\left(x, x_{2 n-1}\right)\right) d\left(x, x_{2 n-1}\right)+\left(1-\phi\left(d\left(x, x_{2 n-1}\right)\right)\right) d(A, B) \\
& \leqslant d\left(x, x_{2 n}\right)+\phi\left(d\left(x, x_{2 n-1}\right)\right)\left(d\left(x, x_{2 n-1}\right)-d(A, B)\right)+d(A, B) .
\end{aligned}
$$

Taking limit $\mathrm{n} \rightarrow \infty$ in the above inequality and using (2.16) and (2.17), we have

$$
d(A, B) \leqslant d(x, T x) \leqslant d(A, B),
$$

which implies that $d(x, T x)=d(A, B)$, that is, $x$ is a best proximity point of $T$ in $A$.

Corollary 2.2. Let $(\mathrm{X}, \mathrm{d}, \preceq)$ be a partially ordered complete metric space and $\mathrm{A}$ and $\mathrm{B}$ be two nonempty closed subsets of $X$ such that $(A, B)$ and $(B, A)$ satisfy the property $U C$. Let $T: A \cup B \rightarrow C B(A) \cup C B(B)$ be a multivalued cyclic mapping. Let $\mathrm{T}$ satisfy the following assumptions:

(i) $\mathrm{T}$ is approximately monotone increasing;

(ii) there exists $x_{0} \in A$ and $x_{1} \in B$ such that $x_{0} \preceq x_{1}$ and $x_{1} \in T x_{0}$;

(iii) the inequality (2.1) is satisfied for $x \in A$ and $y \in B$, either $x \preceq y$ or $y \preceq x$ and $\phi$ is a MT -function;

(iv) for any monotone increasing sequence $\left\{x_{n}\right\} \subset X$ with $\left\{x_{n}\right\} \rightarrow x$ as $n \rightarrow \infty$, it proves that $x_{n} \preceq x$.

Then $\mathrm{T}$ has a best proximity point in $\mathrm{A}$.

Proof. Since an approximately monotone increasing mapping is also a partly monotone increasing mapping, the proof follows by an application of Theorem 2.1.

Example 2.3. Let $d(X, d)$ be a metric with $X=R^{2}$ and

$$
d\left(\left(x_{1}, y_{1}\right),\left(x_{2}, y_{2}\right)\right)=\left|x_{1}-x_{2}\right|+\left|y_{1}-y_{2}\right| \text { for all }\left(x_{1}, x_{2}\right),\left(y_{1}, y_{2}\right) \in R^{2} \text {. }
$$

Let $A=(-\infty,-1] \times R$ and $B=[1, \infty) \times R$.

Here $d(A, B)=2$ and $(A, B)$ and $(B, A)$ satisfy the property $U C$.

We define a partial order on $X$ as $\left(x_{1}, y_{1}\right) \preceq\left(x_{2}, y_{2}\right)$ iff either $x_{1}=x_{2}$ and $y_{1}=y_{2}$ or $y_{1}>y_{2}$ and $x_{1}$ and $x_{2}$ are rational numbers.

Define the cyclic mapping $\mathrm{T}: \mathrm{A} \cup \mathrm{B} \rightarrow \mathrm{CB}(\mathrm{A}) \cup \mathrm{CB}(\mathrm{B})$ by

$$
\mathrm{T}(x, y)= \begin{cases}\left\{\left(p, \frac{y}{2}\right): 1 \leqslant p \leqslant \frac{1-x}{2}\right\}, & \text { if }(x, y) \in A \text { and } y \text { is rational, } \\ \left\{\left(p, \frac{y}{2}\right): \frac{-1-x}{2} \leqslant p \leqslant-1\right\}, & \text { if }(x, y) \in B \text { and } y \text { is rational, } \\ \{(\sqrt{2}, p): 1 \leqslant p \leqslant 2\}, & \text { if }(x, y) \in A \text { and } x \text { is irrational, } \\ \{(-\sqrt{2}, p): 1 \leqslant p \leqslant 2\}, & \text { if }(x, y) \in B \text { and } x \text { is irrational. }\end{cases}
$$


$\mathrm{T}$ is a partly monotone increasing mapping which follows by the following observation.

Let $p=(x, y) \in A$. Let $q \in T p$ such that $p \preceq q$. Then $x$ is rational and $q=\left(z, \frac{y}{2}\right)$ where $z$ is a rational number with $1 \leqslant z \leqslant \frac{1-x}{2}$.

Then it is possible to find a rational number $\omega$ such that $\frac{-z-1}{2} \leqslant \omega \leqslant-1$. Then $r=\left(\omega, \frac{y}{4}\right) \in \operatorname{Tq}$ such that $q \preceq r$. The case where $p=(x, y) \in B$ is similar.

Further with any $p_{0}=\left(x_{0}, y_{0}\right) \in A$ with $x_{0}$ rational, we can find $r_{0}=\left(x_{1}, y_{1}\right) \in T p_{0}$ with $x_{1}=\frac{1+x_{0}}{2}$ and $y_{1}=\frac{y_{0}}{2}$ such that $p_{0} \preceq r_{0}$.

Also the inequality (2.1) is satisfied for any $p \in A$ and $q \in B$ with either $p \preceq q$ or $q \preceq p$ with

$$
\phi(t)= \begin{cases}k t, & \text { if } 0 \leqslant k \leqslant 1 \\ \frac{1}{2}, & \text { if } t>1, \text { where } 0<k<1\end{cases}
$$

Then by an application of Theorem 2.1, there exists a best proximity point of $\mathrm{T}$ in $\mathrm{A}$.

Remark 2.4. In the above example, the inequality is not satisfied for arbitrary choices of $x \in A$ and $y \in B$. Further, the inequality is also not satisfied for arbitrary choices of $p$ and $q$ with the following $q \in T p$. We also see that the multivalued function $\mathrm{T}$ is discontinuous.

Corollary 2.5. Let $(X, \mathrm{~d})$ be a complete metric space and $(\mathrm{A}, \mathrm{B})$ be a pair of nonempty closed subsets of $\mathrm{X}$. Let $\mathrm{T}: \mathrm{A} \cup \mathrm{B} \rightarrow \mathrm{A} \cup \mathrm{B}$ be a cyclic mapping such that

(i) $\mathrm{T}$ is monotone increasing (Definition 1.5);

(ii) there exists $x_{0} \in A$ such that $x_{0} \preceq x_{1}$ for some $x_{1} \in B$;

(iii) when $x \in A$ and $y \in B$, either $x \preceq y$ or $y \preceq x$ and $\phi$ is a MT-function

$$
d(T x, T y) \leqslant \phi(d(x, y)) d(x, y)+(1-\phi(d(x, y))) d(A, B) .
$$

Also for any monotone increasing sequence $\left\{x_{n}\right\} \rightarrow x, x_{n} \preceq x$ for all $x$.

Then $\mathrm{T}$ has a best proximity point in $\mathrm{A}$.

Remark 2.6. Corollary 2.5 is a generalization of [15] and [16] in partially ordered metric spaces.

Example 2.7. Let $d(X, d)$ be a metric with $X=R^{2}$ and

$$
d\left(\left(x_{1}, y_{1}\right),\left(x_{2}, y_{2}\right)\right)=\left|x_{1}-x_{2}\right|+\left|y_{1}-y_{2}\right| \text { for all }\left(x_{1}, x_{2}\right),\left(y_{1}, y_{2}\right) \in R^{2}
$$

Let $A=(-\infty,-1] \times R$ and $B=[1, \infty) \times R$.

Here $d(A, B)=2$ and $(A, B)$ and $(B, A)$ satisfy the property $U C$.

We define a partial order on $X$ as $\left(x_{1}, y_{1}\right) \preceq\left(x_{2}, y_{2}\right)$ iff either $x_{1}=x_{2}, y_{1}=y_{2}$ or $-1-\frac{\left|x_{1}-1\right|}{2} \leqslant x_{2} \leqslant$ $1+\frac{\left|x_{1}-1\right|}{2},\left|y_{1}\right|>\left|y_{2}\right|$.

Define the cyclic mapping $T: A \cup B \rightarrow C(A) \cup C(B)$ by

$$
T(x, y)= \begin{cases}\left\{\left(p, \frac{y}{2}\right): 1 \leqslant p \leqslant \frac{1-x}{2}\right\}, & \text { if }(x, y) \in A \\ \left\{\left(p, \frac{y}{2}\right): \frac{-1-x}{2} \leqslant p \leqslant-1\right\}, & \text { if }(x, y) \in B\end{cases}
$$

Let

$$
\phi(t)= \begin{cases}k t, & \text { if } 0 \leqslant k \leqslant 1 \\ \frac{1}{2}, & \text { if } t>1, \text { where } 0<k<1\end{cases}
$$

Then $\mathrm{T}$ is approximately monotone increasing and Corollary 2.2 is applicable to this example.

Remark 2.8. T is not monotone increasing (Definition 1.5). Therefore Corollary 2.5 is not applicable. 


\section{Acknowledgment}

The second author would like to extend his sincere appreciation to the Deanship of Scientific Research at King Saud University for its funding of this Prolific Research group (PRG-1436-20).

\section{References}

[1] A. Abkar, M. Gabeleh, Best proximity points for cyclic mappings in ordered metric spaces, J. Optim. Theory Appl., 150 (2011), 188-193. 1

[2] A. Abkar, M. Gabeleh, Generalized cyclic contractions in partially ordered metric spaces, Optim. Lett., 6 (2011), 18191830. 1

[3] R. P. Agarwal, M. A. El-Gebeily, D. O’Regan, Generalized contractions in partially ordered metric spaces, Appl. Anal., 87 (2008), 109-116. 1

[4] M. A. Al-Thagafi, N. Shahzad, Convergence and existence results for best proximity points, Nonlinear Anal., 70 (2009), 3665-3671. 1

[5] B. S. Choudhury, A. Kundu, $(\psi, \alpha, \beta)$-weak contractions in partially ordered metric spaces, Appl. Math. Lett., 25 (2012), 6-10. 1

[6] B. S. Choudhury, P. Maity, Coupled fixed point results in generalized metric spaces, Math. Comput. Modelling, 54 (2011), 73-79. 1

[7] B. S. Choudhury, P. Maity, P. Konar, A global optimality result using nonself mappings, Opsearch, 51 (2014), $312-320$. 1

[8] B. S. Choudhury, P. Maity, N. Metiya, Best proximity point theorems with cyclic mappings in setvalued analysis, Indian J. Math., 57 (2015), 79-102. 1

[9] B. S. Choudhury, P. Maity, N. Metiya, Best proximity point results in set-valued analysis, Nonlinear Anal. Model. Control, 21 (2016), 293-305. 1

[10] L. Ćirić, Fixed point theorems for multi-valued contractions in complete metric spaces, J. Math. Anal. Appl., 348 (2008), 499-507 . 1

[11] L. Ćirić, N. Cakić, M. Rajović, J. S. Ume, Monotone generalized nonlinear contractions in partially ordered metric spaces, Fixed Point Theory Appl., 2008 (2008), 11 pages. 1

[12] M. De la Sen, S. L. Singh, M. E. Gordji, A. Ibeas, R. P. Agarwal, Best proximity and fixed point results for cyclic multivalued mappings under a generalized contractive condition, Fixed Point Theory Appl., 2013 (2013), 21 pages. 1

[13] C. Di Bari, T. Suzuki, C. Vetro, Best proximity points for cyclic Meir-Keeler contractions, Nonlinear Anal., 69 (2008), 3790-3794. 1

[14] W.-S. Du, On coincidence point and fixed point theorems for nonlinear multivalued maps, Topology Appl., 159 (2012), 49-56. 1, 1.10

[15] W.-S. Du, H. Lakzian, Nonlinear conditions for the existence of best proximity points, J. Inequa. Appl., 2012 (2012), 7 pages. $1,2.6$

[16] A. A. Eldred, P. Veeramani, Existence and convergence of best proximity points, J. Math. Anal. Appl., 323 (2006), 1001-1006. 1.2, 2.6

[17] K. Fan, Extensions of two fixed point theorems of F. E. Browder, Math. Z., 122 (1969), 234-240. 1

[18] M. Jleli, B. Samet, Best proximity point results for MK-proximal contractions on ordered sets, J. Fixed Point Theory Appl., 17 (2015), 439-452. 1

[19] E. Karapınar, Best proximity points of cyclic mappings, Appl. Math. Lett., 25 (2012), 1761-1766. 1

[20] E. Karapınar, G. Petruşel, K. Tas, Best proximity point theorems for KT-types cyclic orbital contraction mappings, Fixed Point Theory, 13 (2012), 537-546. 1

[21] W. A. Kirk, S. Reich, P. Veeramani, Proximinal retracts and best proximity pair theorems, Numer. Funct. Anal. Optim., 24 (2003), 851-862. 1

[22] N. Mizoguchi, W. Takahashi, Fixed point theorems for multivalued mappings on complete metric spaces, J. Math. Anal. Appl., 141 (1989), 177-188. 1, 1.9

[23] S. B. Nadler Jr., Multi-valued contraction mappings, Pacific J. Math., 30 (1969), 475-488. 1.3, 1

[24] K. Neammanee, A. Kaewkhao, Fixed points and best proximity points for multi-valued mapping satisfying cyclical condition, Int. J. Math. Sci. Appl., 1 (2011), 9 pages. 1.4

[25] V. Pragadeeswarar, M. Marudai, Best proximity points: approximation and optimization in partially ordered metric spaces, Optim. Lett., 7 (2012), 1883-1892. 1

[26] W. Sintunavarat, P. Kumam, Coupled best proximity point theorem in metric spaces, Fixed Point Theory Appl., 2012 (2012), 16 pages. 1

[27] T. Suzuki, M. Kikkawa, C. Vetro, The existence of best proximity points in metric spaces with the property UC, Nonlinear Anal., 71 (2009), 2918-2926. 1, 1.8, 1.11

[28] M. Turinici, Abstract comparison principles and multivariable Gronwall-Bellman inequalities, J. Math. Anal. Appl., 117 (1986), 100-127. 1 